\title{
LATE-ONSET HEMATOLOGICAL TOXICITY (LOHT) IN PATIENTS WITH B-CELL LYMPHOMAS: A SURVEY IN 758 CASES
}

\author{
Adriana Palacios-Campos ${ }^{1}$, Alfonso Dueñas-GonzálezZ ${ }^{1,2}$, Olga Gutiérrez-Hernández ${ }^{1}$, \\ and Myrna Candelaria- HeRnández ${ }^{1 *}$ \\ ${ }^{1}$ Department of Clinical Research, Instituto Nacional de Cancerología, Mexico City; ${ }^{2}$ Instituto de Investigaciones \\ Biomédicas, Universidad Nacional Autónoma de México, Mexico City, Mexico
}

\begin{abstract}
Background: The increasing survival of patients with non-Hodgkin lymphoma has allowed the diagnosis of long-term complications, including late-onset hematological toxicity (LOHT), transitory cytopenias, or therapy-related myeloid neoplasm (t-MDS/t-AML). Objective: The objective of the study was to determine the frequency and clinical evolution of LOHT in patients with lymphoproliferative malignancies. Materials and Methods: Two cohorts of patients B-cell lymphomas were reviewed. Patients who achieved full hematologic recovery at the end of treatment, and thereafter developed any degree of cytopenia were included in the study. Clinical and biochemical parameters were compared between patients with and without cytopenias with X2 test. Bi- and multivariate analyses were performed to evaluate factors associated with the development of late-onset cytopenias. Results: Of 758 patients enrolled, 19 developed cytopenias (2.5\%). Transitory cytopenia was documented in 6 cases, 3 developed ICUS, 8 t-MDS, and 2 t-AML. In patients with FL, only hemoglobin $<12 \mathrm{~g} / \mathrm{dL}(\mathrm{p}=0.032)$ and $>6$ nodal areas $(p=0.037)$ at diagnosis were factors statistically significant for the development of cytopenia. During cytopenias, $55 \%$ of patients died. Conclusions: LOHT constitutes a cause of morbidity and mortality in $2.5 \%$ of lymphoma patients treated with different therapy regimens. (REV INVEST CLIN. 2021;73(2):72-8)
\end{abstract}

Key words: Transitory cytopenias. Therapy-related myeloid neoplasm (t-MDS/t-AML). B-cell lymphomas. Late-onset toxicity.

\section{INTRODUCTION}

The increase on survival rate of patients with nonHodgkin lymphoma has allowed the diagnosis of longterm complications, including transitory cytopenias and therapy-related myeloid neoplasms ( $\mathrm{t}-\mathrm{MN}$ : t-MDS/ $\mathrm{t}-\mathrm{AML})^{1,2}$. Progenitor stem cells are truly sensitive to damage caused by chemotherapy; there are different degrees of toxicity to the same chemotherapy schedule between populations ${ }^{2-5}$.

The incidence of $\mathrm{t}-\mathrm{MN}$ after conventional therapy ranges from $0.8 \%-6.3 \%$ to 20 years and may result from an impaired ability to detoxify chemotherapeutic drugs or repair drug-induced genetic damage caused by genetic polymorphisms in enzymes involved in the
*Corresponding author:

Myrna Candelaria-Hernández

E-mail: candelariahmgloria@gmail.com
Received for publication: 13-07-2020

Approved for publication: 18-08-2020

DOI: $10.24875 / R I C .20000351$

0034-8376 / (c) 2020 Revista de Investigación Clínica. Published by Permanyer. This is an open access article under the CC BY-NC-ND license (http://creativecommons.org/licenses/by-nc-nd/4.0/). 
metabolism of drugs ${ }^{1}$. t-MDS/t-AML are an evident cause of long-term, non-relapse mortality ${ }^{5,6}$.

Rituximab is a monoclonal antibody widely used for the treatment of different B-cell neoplasms, and even though it has not been associated with acute myelosuppression 7 , late-onset cytopenias (LOC), such as neutropenia, has been described with a postcommercialization rate of $0.02 \%$ in more than 30,000 patients, but according to different publications, this rate is higher. A single study has also described neutropenia in $9 \%$ of patients and a decrease of up to $30 \%$ from the baseline platelets ${ }^{8}$. Most of LOC are self-limited and have a spontaneous regression. However, they also may have an impact on long-term survival, since according to their severity, patients may have a higher risk of infections and may require transfusion of blood-derived products. To determine the frequency and clinical evolution of LOHT in patients with lymphoproliferative malignancies, two cohorts of patients with follicular and diffuse large B cell lymphomas were reviewed.

\section{MATERIALS AND METHODS}

Two cohorts of patients B-cell lymphomas attending from January 2011 to December 2015 at the Instituto Nacional de Cancerología México were reviewed. Late-onset hematological toxicity was defined as any cytopenia, developed after complete hematological response lasting at least 2 months, and was classified in three groups: (1) late-onset transitory cytopenia (LOC) defined as any self-limited cytopenia (1), (2) idiopathic cytopenia of unknown significance (ICUS) defined as peripheral cytopenia, not self-limited, not fulfilling MDS criteria, no MDS-related mutation ${ }^{9}$, and (3) therapy related-myeloid neoplasms (t-MN) were defined as patients who develop t-MDS/t-AML myelodysplasia ( $t-M D S$ ) or acute leukemia ( $t-A M L)$ after exposure to cytotoxic or radiation therapy for an unrelated malignancy ${ }^{2}$.

\section{Inclusion criteria}

Age $\geq 18$ years, diagnosis of either follicular lymphoma (FL) or diffuse large B-cell lymphoma ( $\mathrm{DLBCL}$ ), treated with rituximab based schemas, achievement of complete hematologic recovery at the end of treatment ${ }^{10}$, and thereafter, developed any degree of cytopenia. We excluded patients with HIV or other infections, hepatopathy, uncontrolled thyroid disease, active immune diseases, any active neoplasm, or other hematologic diseases or recent exposition to myelotoxic. In all patients, peripheral blood smear and bone marrow examination with cytogenetic analysis were performed. Cytopenias were defined according with CTCAE v. 4 criteria $^{10}$ as: neutropenia as neutrophils $<1500 / \mathrm{mm}^{3}$, anemia as hemoglobin $<11.0 \mathrm{~g} / \mathrm{dL}$, and thrombocytopenia as platelets $<100,000 \mathrm{~mm}^{3}$.

\section{Clinical parameters}

That was analyzed included sex, age, B-symptoms, Eastern Cooperative Oncology Group (ECOG) performance status ${ }^{11}$, clinical-stage by Lugano classification $^{12}$, the presence of bone marrow infiltration, bulky disease, number of nodal sites at diagnosis, International Prognostic Index (IPI score) for DLBCL, Follicular Lymphoma International Prognostic Index (FLIPI score) for FL, date of diagnosis, response to treatment ${ }^{12}$, date of relapse, date of mortality, and last hospital visit. Baseline levels biochemical parameters analyzed included: lactic dehydrogenase (LDH), $\beta 2$ microglobulin $(\beta 2 \mathrm{mcg})$, serum albumin, hemoglobin, absolute leukocyte, neutrophil, and lymphocyte counts.

\section{Treatment protocols for DLBCL included the following ${ }^{13-15}$}

RCHOP (375 mg/m² rituximab, $750 \mathrm{mg} / \mathrm{m}^{2}$ cyclophosphamide, $50 \mathrm{mg} / \mathrm{m}^{2}$ doxorubicin, $1.4 \mathrm{mg} / \mathrm{m}^{2}$ vincristine [maximal total dose: $2 \mathrm{mg}$ ], and $100 \mathrm{mg} /$ day $/ 5$ days prednisone), DA-EPOCH-R $\left(375 \mathrm{mg} / \mathrm{m}^{2}\right.$ rituximab; $50 \mathrm{mg} / \mathrm{m}^{2}$ etoposide, daily in $96 \mathrm{~h}$ continuous infusion; $10 \mathrm{mg} / \mathrm{m}^{2}$ doxorubicin, daily in $96 \mathrm{~h}$ continuous infusion; $0.4 \mathrm{mg} / \mathrm{m}^{2}$ vincristine, daily in $96 \mathrm{~h}$ continuous infusion; and $750 \mathrm{mg} / \mathrm{m}^{2}$ cyclophosphamide, on day 5), R-CVP (375 mg/m² rituximab, $750 \mathrm{mg} / \mathrm{m}^{2}$ cyclophosphamide, $1.4 \mathrm{mg} / \mathrm{m}^{2}$ vincristine [maximal total dose: $2 \mathrm{mg}$ ], and $100 \mathrm{mg} /$ day/5 days prednisone), R-high dose methotrexate $\left(375 \mathrm{mg} / \mathrm{m}^{2}\right.$ rituximab and methotrexate $1-3 \mathrm{~g} / \mathrm{m}^{2}$ ), and R-ICE ( $375 \mathrm{mg} / \mathrm{m}^{2}$ rituximab, $5 \mathrm{~g} / \mathrm{m}^{2}$ ifosfamide on day 4 , carboplatin AUC $=5$ on day 4 , and $100 \mathrm{mg} / \mathrm{m}^{2}$ etoposide on day 3-5). 


\section{Treatment schemas for follicular lymphoma included}

R-bendamustine ( $375 \mathrm{mg} / \mathrm{m}^{2}$ rituximab and $90 \mathrm{mg} /$ $\mathrm{m}^{2}$ bendamustine on days $\left.1-2\right), \mathrm{FCR}\left(375 \mathrm{mg} / \mathrm{m}^{2}\right.$ rituximab, $25 \mathrm{mg} / \mathrm{m}^{2}$ fludarabine on days $2-4$, and $250 \mathrm{mg} / \mathrm{m}^{2}$ cyclophosphamide on days $2-4$ ), R-ESHAP $\left(375 \mathrm{mg} / \mathrm{m}^{2}\right.$ rituximab, $40 \mathrm{mg} / \mathrm{m}^{2}$ etoposide on day $1-4,25 \mathrm{mg} / \mathrm{m}^{2}$ cisplatin on day $1-4$, and $2 \mathrm{~g} / \mathrm{m}^{2}$ cytarabine on day 5), and RCHOP, as previously described. The addition of radiotherapy (dose and site) was given according to clinical indication.

The response to treatment was evaluated using standard international criteria. For patients in whom PET/ CT was performed before and after treatment, Deauville criteria were used (12). In cases with increased blood glucose levels ( $>170 \mathrm{mg} / \mathrm{dL}$ ), which contraindicated the performance of PET/CT, only a CT was performed, and the response was evaluated by standard Cheson criteria ${ }^{12}$.

\section{Ethical aspects}

This is a retrospective study. The review of clinical files had the corresponding IRB approval (REV 003/19).

\section{Statistical analysis}

Baseline descriptive analysis was performed; including quantitative and qualitative variables were done; clinical and biochemical parameters were compared between patients with and without cytopenias with $\mathrm{X}^{2}$ test. $\mathrm{Bi}$ - and multivariate analyses were performed to evaluate factors associated with the development of late-onset cytopenias. Factors analyzed included: gender, B symptoms, bulky disease, clinical stage, number of nodal sites at diagnosis, ECOG score, bone marrow infiltration, and biochemical parameters (increased LDH, increased $\beta 2$-microglobulin, hemoglobin, albumin, leukocytes, neutrophil, and lymphocytes values), (IPI score) for DLBCL, and (FLIPI score) for FL. Odds ratios (OR) and their respective $95 \%$ confidence interval $(\mathrm{Cl})$ were calculated to identify associations. Overall survival (OS) was calculated using the Kaplan-Meier method. Cumulative incidence was also calculated for t-MDS and t-AML. Statistical analysis was performed using SPSS (version 20; IBM Corp., Armonk, NY, USA).

\section{RESULTS}

From January 2011 to December 2015, 840 patients (695 with DLBCL and 145 with FL attended at this Institution). Of them, 758 (626 DLBL and $132 \mathrm{FL}$ ) were included in this analysis. No difference within clinical or biochemical values was found between the patients with or without LOHT. In the whole group, $60 \%$ received chemotherapy and radiotherapy and $33.4 \%$ received only chemotherapy. No difference within treatment intensity was documented between patients with and without LOHT.

During a mean follow-up of 54 months, as detailed in Figure 1, 19 patients developed LOHT (2.5\%) (11 with $\mathrm{DLBCL}$ and 8 with $\mathrm{FL})$. The most frequent cytopenia was neutropenia in DLBCL $(n=3,27.2 \%)$ and pancytopenia in FIL $(n=4,50 \%)$. Seven patients (36.8\%) were hospitalized because of febrile neutropenia ( 1 with transitory cytopenia and 6 with t-MN); 3 patients required transfusion: 1 patient with t-MN required platelet transfusion (9.7 units); and 2 patients with $\mathrm{t}-\mathrm{MN}$ required red blood cells (RBC) (mean 5 units). During cytopenia 11 patients died (57.9\%); the causes were: t-AML $(n=4,21 \%), t-M D S(n=4$, $21 \%)$, and fever and neutropenia $(n=3,15.7 \%)$; no patients in the group of transitory cytopenia died. For those patients with transitory cytopenias, median time to the presentation of cytopenia was 24.5 months since the last chemotherapy with a median time to recovery of 6 months. Meantime to presentation for patients with t-MDS (after last chemotherapy) was 8.5 months, and for patients with t-AML mean time to presentation was 21 months.

\section{Evolution of LOHT}

Of the 19 patients with cytopenias, ten patients developed therapy related-myeloid neoplasms ( $\mathrm{t}-\mathrm{MN}$ ): $8 \mathrm{t}-\mathrm{MDS}$ and $2 \mathrm{t}$-AML. The detailed clinical evolution of these cases is shown in Table 1. Both patients who developed t-AML (patients 1 and 2 died after 7 and 8 months due to infections and bleeding, respectively. Five patients with t-MDS also died and the rest of patients with t-MDS remain alive to a mean follow-up of 10.2 months (range: 4-29).

Three patients with $\mathrm{FL}$ relapsed after 10, 12, and 25 months of the development of LOC; at relapse, these patients had already recovered from cytopenias. 
Figure 1. Distribution of cytopenias in patients with diffuse large B cell lymphoma and follicular lymphoma. *We excluded developed cytopenias due to vitamin deficiencies, bone marrow hypoplasia, thyroid disease, hypersplenism, among other peripheral causes of cytopenias. DLBCL (diffuse large B cell lymphoma), FL (follicular lymphoma), ICUS (idiopathic cytopenia of undetermined significance), t-MN (therapy-related myeloid neoplasms), t-MDS (therapy-related myelodysplastic syndrome), t-AML (therapy-related acute myeloid leukemia).

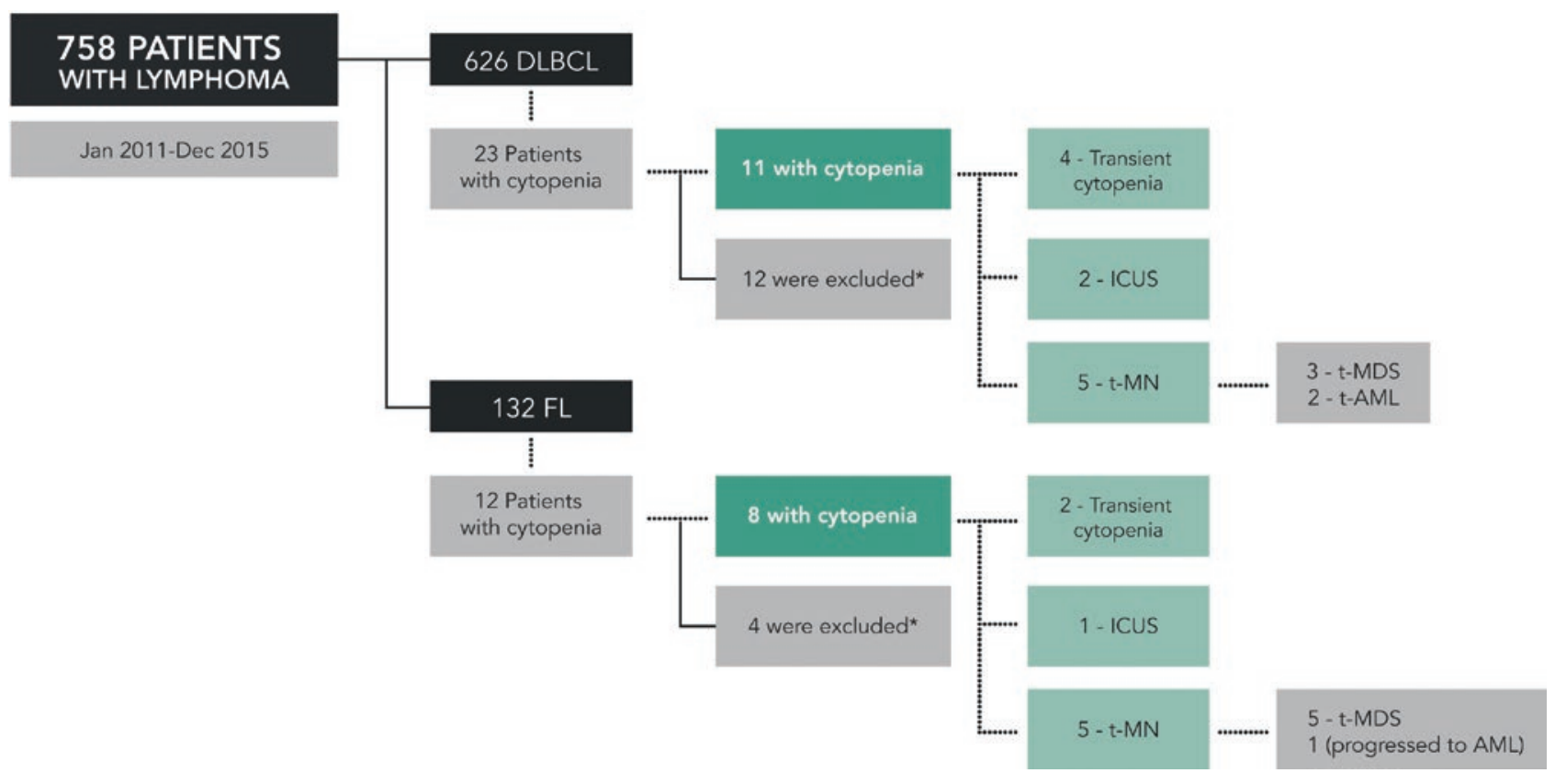

\section{Risk factors to develop LOHT}

After bivariate analysis, only hemoglobin $<12 \mathrm{~g} / \mathrm{dL}$ (OR: 3.59 , [95\% confidence interval: 10.93-15.35]) $(p=0.032)$ and $\geq 6$ nodal sites $(p=0.037)$ (OR: 7.01 , $95 \%$ confidence interval: $5.72-15-19)$ at diagnosis were associated with LOHT in patients with follicular lymphoma. After multivariate analysis, no risk factor was associated with the presence of cytopenias. In FL, the presence of LOHT was associated with an increased rate of relapse: $54.5 \%$ versus $13.6 \%$ in patients without cytopenias $(p=0.002)$. In patients with DLBCL, the development of LOHT was not associated with an increase of relapse rate.

\section{Survival}

As shown in Figure 2, mean overall survival (OS) has not been achieved at 60 months in patients with LOHT. In the group of patients with t-MDS, mean OS has neither been achieved and was similar to those patients with ICUS or transitory cytopenia. However, the median OS was 5.2 months in patients with $\mathrm{t}-\mathrm{AML}$. Therefore, the development of transitory cytopenia, ICUS, or t-MDS has a negative impact on overall survival.

\section{DISCUSSION}

Hematopoietic stem cells are particularly sensible to chemotherapy and there is also a wide grade of response in terms of toxicity between patients ${ }^{7}$. Since the last decade, with the increasing use of rituximab as monotherapy or as part of different chemotherapy schedules, there is an increased survival in patients with B cell lymphomas and there are still many questions about the late adverse effects of this antibody. Late-onset neutropenia was initially described to be asymptomatic in patients treated with rituximab, but in our group of patients, there is a high incidence of infections $(22.8 \%)$ requiring hospitalization, which also increases morbidity and health costs ${ }^{16-17}$.

According to different studies ${ }^{16-21}$, the following risk factors have been associated as risk factors for cytopenias: age, gender, lymphoma subtype, bone marrow infiltration, hypogammaglobulinemia, previous 
Table 1. Patients with t-MN described individually

\begin{tabular}{|c|c|c|c|c|c|c|c|c|c|c|}
\hline Patient & $1^{\mathrm{a}}$ & $2^{\mathrm{a}}$ & $3^{a}$ & $4^{a}$ & $5^{a}$ & $6^{b}$ & $7^{b}$ & $8^{b}$ & $9^{b}$ & $10^{\mathrm{b}}$ \\
\hline $\begin{array}{l}\text { Age at diagnosis } \\
\text { of lymphoma }\end{array}$ & 83 & 59 & 58 & 70 & 63 & 62 & 61 & 68 & 62 & 51 \\
\hline $\begin{array}{l}1^{\text {st }} \text { line therapy: } \\
\text { R-CHOP } \\
\text { (number of cycles) }\end{array}$ & 6 & 8 & 4 & 6 & 6 & 7 & 8 & 8 & 8 & 8 \\
\hline $2^{\text {nd }}$ line therapy & - & - & - & - & - & FCR & FCR & R-Mitoxantrone & Rituximab & FCR \\
\hline $\begin{array}{l}\text { Number of } \\
\text { chemotherapy lines }\end{array}$ & 1 & 1 & 1 & 1 & 1 & 2 & 3 & 2 & 5 & 2 \\
\hline Radiotherapy & 30 Gys & 30 Gys & No & No & 36 Gys & 30 Gys & 36 Gys & 30 Gys & 24 Gys & 30 Gys \\
\hline $\begin{array}{l}\text { Months between } \\
\text { full hematologic } \\
\text { recovery and event }\end{array}$ & 20 & 25 & 15 & 7 & 2 & 15 & 1 & 11 & 14 & 2 \\
\hline t-MDS subtype & - & - & MDS-MLD & MDS-MLD & MDS-MLD & MDS-MLD & MDS-MLD & MDS-MLD & MDS-MLD & MDS-MLD \\
\hline $\begin{array}{l}\text { MDACC risk } \\
\text { model score }\end{array}$ & - & - & Intermediate & Good & Intermediate & Intermediate & Intermediate & Poor & Intermediate & Poor \\
\hline Karyotype & $\begin{array}{l}\text { Complex } \\
\text { karyotype }\end{array}$ & NA & $(-7,-13)$ & Normal & $\begin{array}{l}\text { Complex } \\
\text { karyotype }\end{array}$ & $\begin{array}{l}\text { Complex } \\
\text { karyotype }\end{array}$ & NA & Normal & $\begin{array}{l}92, \mathrm{XXXX}[8] / \\
46, \mathrm{XX}[10]\end{array}$ & $47 x x+11$ \\
\hline t-AML subtype & MO & M4 E0 & - & - & - & - & - & - & - & - \\
\hline Therapy & Cytarabine & Cytarabine & Support & Danazol & G-CSF & G-CSF & Support & Azacitidine & Azacitidine & Support \\
\hline $\begin{array}{l}\text { Response } \\
\text { to therapy }\end{array}$ & NR & NR & NR & $\mathrm{HI}$ & $\mathrm{HI}$ & $\mathrm{HI}$ & $\mathrm{HI}$ & NA & Failure & $\begin{array}{l}\text { Progression } \\
\text { t-AML M6 }\end{array}$ \\
\hline $\begin{array}{l}\text { Actual status/ } \\
\text { months since } \\
\text { t-MN diagnosis }\end{array}$ & $\begin{array}{l}\text { Dead/ } \\
7 \text { months }\end{array}$ & $\begin{array}{l}\text { Dead/ } \\
8 \text { months }\end{array}$ & $\begin{array}{l}\text { Dead/ } \\
1 \text { month }\end{array}$ & $\begin{array}{l}\text { Alive/ } \\
11 \text { months }\end{array}$ & $\begin{array}{l}\text { Alive/ } \\
4 \text { months }\end{array}$ & $\begin{array}{l}\text { Alive/ } \\
4 \text { months }\end{array}$ & $\begin{array}{l}\text { Alive/ } \\
29 \text { months }\end{array}$ & $\begin{array}{l}\text { Dead/ } \\
3 \text { months }\end{array}$ & $\begin{array}{l}\text { Dead/ } \\
3 \text { months }\end{array}$ & $\begin{array}{l}\text { Dead/11 } \\
\text { months }\end{array}$ \\
\hline
\end{tabular}

${ }^{a}$ DLBCL: diffuse large B cell lymphoma; ${ }^{b}$ FL: follicular lymphoma; R-CHOP: rituximab, cyclophosphamide, doxorubicin, vincristine, and prednisone; FCR: fludarabine, cyclophosphamide, rituximab; Gys: unit used to measure the total about of radiation the patient is exposed to; t-MDS: therapy-related myelodysplastic syndrome; MDS-MLD: myelodysplastic syndrome with multilineage

dysplasia; MDACC: The University of Texas M. D. Anderson Cancer Center risk model; NA: not available; t-AML: therapy-related acute myeloid leukemia; MO: minimally differentiated AML;

M4EO: myelomonocytic leukemia with eosinophilia; G-CSF: granulocyte colony-stimulating factor; NR: no response; HI: hematologic improvement; t-AML M6: erythroleukemia; t-MN: therapyrelated myeloid neoplasms. 
Figure 2. Overall survival in patients with diffuse large B cell lymphoma and follicular lymphoma with late-onset cytopenias.

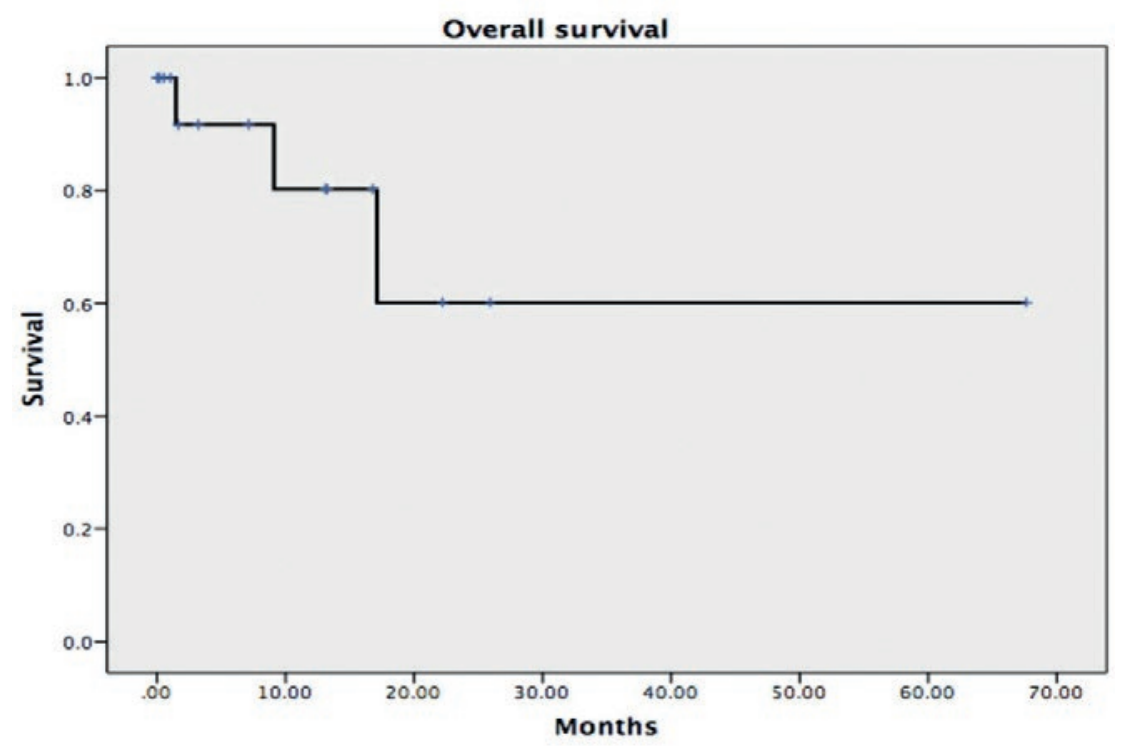

chemotherapy, bone marrow transplant, previous exposition to fludarabine, and time of exposition to rituximab 22 .

Transitory thrombocytopenia has been identified by Wilop et al. ${ }^{23}$, in a cohort of patients with DLBCL, found in up to $7.2 \%$ of the patients with a $30 \%$ reduction of platelet baseline count, either when rituximab was given as a single agent or in combination with chemotherapy. No prospective studies have defined it as a long term complication as late-onset neutropenia (LON) ${ }^{24-26}$. In our series, 1 patient with transitory cytopenia required hospitalization due to fever and neutropenia and recovery was documented 1 month later, with no further evidence of new events during follow-up. Fever and neutropenia by itself demonstrate the negative impact of this late-onset complication.

In the literature, other morphologic alterations have been associated with LON, particularly, 4 cases have been described with arrest in differentiation, remaining as promyelocytes, without the presence of large granular lymphocytes, and we were able to identify a patient with this particular morphologic feature $(\text { Table } 1)^{26}$.

Previous studies $19-21,25,26$ reported lower rates of prolonged cytopenias than the ones in our study, probably associated with different characteristics of the populations and that ours is a retrospective cohort, so we propose a further prospective study with close monitorization.

t-MDS was the most common cause of cytopenia in patients with follicular lymphoma, probably associated with multiple line treatments according to more frequent relapses in this particular group of patients. Since fludarabine is suggested as a second-line treatment in this lymphoma, we consider the need of the development of a biomarker able to predict the bone marrow toxicity associated with chemotherapy 22,27 . In the past years, some conditions have been defined as pre-MDS, or ICUS ${ }^{14}$, and even though it has not been studied in patients exposed to chemotherapy, we found that ICUS represented $15.7 \%$ for both lymphomas and this particular group of patients need closer follow-up because progression to $\mathrm{t}-\mathrm{MN}$ is still unknown. In our series, these cases were followed during 3, 5, and 16 months without achieving criteria to be classified as t-MDS or t-AML. Interestingly, only two patients with t-AML have previous DLBCL, apparently without previous myelodysplasia and only one previous line-treatment but were exposed to radiotherapy without other risk factors identified.

Patients with t-MDS do not have a good response to treatment, with overall survival of $62.5 \%$ at 30 months; 
still, the only available prognostic scale for this t-MN needs to be validated in our population to personalize treatment and for evaluation of response.

In conclusion, sample was too small to identify any statistically significant risk factors associated with the development of $\mathrm{t}-\mathrm{MN}$. There is no other study of this kind in our country, so these preliminary results could be the precedent for the creation of a cooperative group for the development of a prospective study to identify the role of late cytopenias in therapy-related myeloid neoplasm ( $t-M N$ ). We aim for the early identification of patients at risk and the personalization of treatment in patients with $\mathrm{t}-\mathrm{MN}$.

\section{REFERENCES}

1. Wolacho O, Bairey O, Lahav M. Late-onset neutropenia after rituximab treatment: case series and comprehensive review of the literature. Medicine (Baltimore). 2010;89:308-18.

2. Candelaria M, Dueñas-González A. Therapy-related myelodysplastic syndrome. Expert Opin Drug Saf. 2015;14:655-65

3. Nilsson C, Hulegårdh E, Garelius H, Möllgard L, Brune M, Wahlin $A$, et al. Secondary acute myeloid leukemia and the role of allogeneic stem cell transplantation in a population-based setting. Biol Blood Marrow Transplant. 2019;15:1770-8.

4. Nasioudis D, Lontos K, Tsagianni A, Boyiadzis M, Ko EM. Acute myeloid leukemia following gynecologic cancer in the era of platinum-based chemotherapy. Int J Gynecol Cancer. 2018; 28:1639-42.

5. Fried S, Avigdor A, Bielorai B, Meir A, Besser MJ, Schachter J, et al. Early and late hematologic toxicity following CD19 CAR-T cells. Bone Marrow Transplant. 2019;54:1643-50.

6. Ganser A, Heuser M. Therapy-related myeloid neoplasms. Curr Opin Hematol. 2017;24:152-8.

7. Salmon JH, Cacoub P, Combe B, Sibilia J, Pallot-PradesB, Fain O, et al. Late-onset neutropenia after treatment with rituximab for rheumatoid arthritis and other autoimmune diseases: data from the autoimmunity and rituximab registry. RMD Open. 2015; 1:e000034.

8. Dunleavy K, Hakim F, Kim HK, Janik JE, Grant N, Nakayama T, et al. B-cell recovery following rituximab-based therapy is associated with perturbations in stromal derived factor-1 and granulocyte homeostasis. Blood. 2005;106:795-802.

9. Valent P. ICUS, IDUS, CHIP and CCUS: diagnostic criteria, separation from MDS and clinical implications. Pathobiology. 2019; 86:30-8.

10. Common Terminology Criteria for Adverse Events (CTCAE) Version 4.0. U.S. Department of Health and Human Services. National Institutes of Health. National Cancer Institute; 2009.

11. Oken MM, Creech RH, Tormey DC, Horton H, Davis TE, McFadden ET, et al. Toxicity and response criteria of the eastern cooperative oncology group. Am J Clin Oncol. 1982;5:649-55.
12. Cheson BD, Ansell S, Schwartz L, Gordon L, Advani R, Jacene H et al. Refinement of the Lugano classification lymphoma response criteria in the era of immunomodulatory therapy. Blood. 2016;128:2489-96

13. Plosker GL, Figgitt DP. Rituximab: a review of its use in NonHodgkin's lymphoma and chronic lymphocytic leukaemia. Drugs. 2003;63:803-43.

14. National Comprehensive Cancer Network. Clinical Practice Guidelines in Oncology. B-Cell Lymphomas; 2020. Available from: https://www.nccn.org/professionals/physician_gls/pdf/ b-cell.pdf. [Last accessed on 2020 May 04].

15. Cheah CY, Herbert K, O’Rourke K, Kennedy GA, George A, Fedele $\mathrm{PL}$, et al. A multicenter retrospective comparison of central nervous system prophylaxis strategies among patients with high-risk diffuse large B-cell lymphoma. Br J Cancer. 2014;111:1072-9.

16. Yamazaki M, Sugiura $H$, Iwatani $Y$, Kyoda M, Nokiba $H$, Amemiya $\mathrm{N}$, et al. Late-onset neutropenia after rituximab treatment for adult-onset nephrotic syndrome. Case Rep Nephrol. 2019; 2019:3580941.

17. Cairoli R, Grillo G, Tedeschi A, D’Avanzo G, Marenco P, Morra E. High incidence of neutropenia in patients treated with rituximab after autologous stem cell transplantation. Haematologica. 2004;89:361-3.

18. Chaiwatanatorn K, Lee N, Grigg A, Filshie R, Firkin F. Delayedonset neutropenia associated with rituximab therapy. $\mathrm{Br} \mathrm{J}$ Haematol. 2003;121:913-8.

19. Lemieux B, Tartas S, Traulle C, Espinouse D, Thieblemont C, Bouafia F, et al. Rituximab-related late-onset neutropenia after autologous stem cell transplantation for aggressive non-Hodgkin's lymphoma. Bone Marrow Transplant. 2004;33:921-3.

20. Fukuno K, Tsurumi H, Ando N, Kanemura N, Goto H, Tanabashi $\mathrm{S}$, et al. Late-onset neutropenia in patients treated with rituximab for Non-Hodgkin's lymphoma. Int J Hematol. 2006;84:242-7.

21. Nitta E, Izutsu K, Sato T, Ota Y, Takeuchi K, Kamijo A, et al. A high incidence of late-onset neutropenia following rituximabcontaining chemotherapy as a primary treatment of CD20positive B-cell lymphoma: a single-institution study. Ann Oncol. 2007;18:364-9.

22. McLaughlin P, Estey E, Glassman A, Romaguera J, Samaniego F, Ayala $A$, et al. Myelodysplasia and acute myeloid leukemia following therapy for indolent lymphoma with fludarabine, mitoxantrone, and dexamethasone (FND) plus rituximab and interferon alpha. Blood. 2005;105:4573-5.

23. Wilop S, Galm O, Dada R, Osieka R, Jost E. Rituximab-associated changes in platelet count in patients with Non-Hodgkin lymphoma. Leuk Lymphoma. 2008;49:2116-24.

24. Hirayama Y, Kohda K, Konuma Y, Hirata Y, Kuroda H, Fujimi H, et al. Late onset neutropenia and immunoglobulin suppression of the patients with malignant lymphoma following autologous stem cell transplantation with rituximab. Intern Med. 2009; 48:57-60

25. Cattaneo C, Spedini P, Casari S, Re A, Tucci A, Borlenghi E, et al. Delayed-onset peripheral blood cytopenia after rituximab: frequency and risk factor assessment in a consecutive series of 77 treatments. Leuk Lymphoma. 2006;47:1013-7.

26. Tesfa D, Gelius T, Sander B, Kimby E, Fadeel B, Palmblad J, et al. Late-onset neutropenia associated with rituximab therapy: evidence for a maturation arrest at the (pro) myelocyte stage of granulopoiesis. Med Oncol. 2008;25:374-9.

27. Cooper JP, Khajaviyan S, Smith SD, Maloney DG, Shustov AR, Warren $\mathrm{EH}$, et al. Outcomes of patients with therapy-related MDS after chemoimmunotherapy for chronic lymphocytic leukemia compared with patients with de novo MDS: a single-institution experience. Clin Lymphoma Myeloma Leuk. 2019; 19:390-5. 